\title{
COMMENTARY
}

\section{Waking up the gut in critically ill patients}

\author{
Juris J Meier* \\ See related review article by Deane et al., http://ccforum.com/content/14/5/228
}

\begin{abstract}
Multiorgan failure frequently develops in critically ill patients. While therapeutic efforts in such patients are often focused on the lungs, on the cardiovascular system as well as on the kidneys, it is important to also consider the functional alterations in gut motility and hormone secretion. Given the central regulatory functions of many gut hormones, such as glucagonlike peptide 1, glucagon-like peptide 2, ghrelin and others, exogenous supplementation of some of these factors may be beneficial under conditions of critical illness. From a pragmatic point of view, the most feasible way towards a restoration of gut hormone secretion in critically ill patients is to provide enteral nutritional supply as soon as possible.
\end{abstract}

Multiorgan failure is a frequent complication in critically ill patients, especially those suffering from systemic inflammatory syndromes $[1,2]$. The functional changes in the affected patients are known to affect primarily the lungs, the cardiovascular system as well as the kidneys. While our therapeutic efforts have therefore often been focused on these organ systems, it seems advisable to also include the gastrointestinal tract in the therapeutic management of critically ill patients [1]. Alterations in gastrointestinal motility are frequently found in such patients, leading to disturbances in nutrient absorption, induction of nausea and an increased risk of aspiration [1]. Furthermore, the gut has long been established as an important immune barrier, providing a safeguard against infectious complications [3]. For these reasons, tight clinical monitoring of gastrointestinal motility is central in the clinical management of critically ill patients, and the advantages of early enteral nutrition versus parenteral nutrient supplementation have been highlighted in numerous previous trials [3].

${ }^{*}$ Correspondence: juris.meier@rub.de

Department of Medicine I, St Josef-Hospital, Ruhr-University Bochum, Gudrunstraße 56, 44791 Bochum, Germany
In the current issue of Critical Care, Dean and colleagues present a concise review that summarises the most important endocrine hormones secreted from the gut and discusses their functional alterations in critically ill patients [1]. Amongst those factors, the most prominent is certainly the incretin hormone glucagon-like peptide (GLP)-1, a 29-amino-acid peptide secreted from intestinal $\mathrm{L}$ cells in response to nutrient ingestion [4]. In healthy individuals, this hormone is partly responsible for the augmentation of insulin responses to glucose and meal ingestion [5]. In addition, GLP-1 might play a role in the so-called ileal brake mechanism; that is, the deceleration of gastric emptying and acid secretion induced by the presence of nutrients in the ileum [6]. There is also good evidence for a role of GLP-1 in the cardiovascular system as well as in the central nervous control of appetite and food intake $[4,7]$.

Owing to its potent glucose-lowering properties, two different types of GLP-1-based therapies have now become available for the treatment of type 2 diabetes. The GLP-1 analogues are injectable agonists at the GLP-1 receptor with a prolonged biological half life, whereas the DPP-4 inhibitors prevent the proteolytic degradation of GLP-1, thereby raising its endogenous plasma concentrations [8]. Because the secretion of GLP-1 is stimulated by the absorption of nutrients from the gut, reductions in GLP-1 plasma concentrations are often caused by alterations in gut motility and absorption [9]. Disturbances in GLP-1 plasma levels are therefore likely to occur in critically ill patients, which are prone to developing abnormal gastrointestinal motility. In particular, the release of incretin hormones is no longer stimulated in patients receiving total parenteral nutrition [10].

What are the potential consequences arising from impaired incretin hormone release in critically ill patients? Most obviously, the stimulation of insulin secretion would be diminished, whereas glucagon levels might increase. Also, the improvements in cardiac function observed during exogenous GLP-1 administration [11] might suggest deteriorations in cardiac functions in patients with low GLP-1 levels, although a role of endogenous GLP-1 in the cardiovascular system has not yet been fully established. On the other hand, reductions in GLP-1 plasma levels might also slightly 
increase appetite and promote gastric emptying, which appears to be rather desirable in critically ill patients.

In light of the potential reductions in GLP-1 concentrations in critically ill patients, and because of the potent glucose-lowering effects of GLP-1 in diabetic patients with no risk of inducing hypoglycaemia [12], the effects of acute intravenous infusions of GLP-1 have been examined in initial proof-of-concept studies in critically ill patients after abdominal surgery [13], after cardiac surgery [14], during parenteral nutrition [10] as well as during enteral feeding [15]. Collectively, these studies have suggested a beneficial role for GLP-1 treatment in critically ill patients.

When considering the exogenous administration of GLP-1 in such patients, however, it is still important to bear in mind that the gut also produces at least 30 to 50 other peptide hormones [16], the physiological functions of which are still not fully elucidated. While the exogenous administration of some of these hormones (for example, ghrelin, GLP-1, GLP-2) may provide certain benefits in terms of glucose homoeostasis, gastric emptying or intestinal epithelial regeneration, mimicking the physiological responses of all major gastrointestinal hormones in critically ill patients is certainly far from realistic. From a pragmatic point of view, the easiest way to normalise the secretion of gastrointestinal hormones in such patients is to provide enteral nutrition as early as possible.

Overall, the review article by Dean and colleagues provides a state-of-the-art overview of our knowledge about the changes in gastrointestinal hormone secretion and action in critically ill patients [1]. At the same time, the complexity of the gut's endocrine network and the multiple biological functions affected by gastrointestinal hormones clearly emphasise the need for further studies in this area in order to gain a better understanding of the biological functions of these hormones and their potential alterations in critically ill patients. Such future studies could then pave the way towards an implementation of gut hormone preparations in the acute management of critical illnesses.

Ultimately, the endocrine failure of the gastrointestinal tract may be considered alongside other endocrine insufficiencies in such patients, such as sympathoadrenal insufficiency [17]. Along these lines, future therapeutic strategies may then also include the substitution of gastrointestinal hormones in critically ill patients, similar to the substitution of corticosteroids in septic patients.

\section{Abbreviations}

Gl, gastrointestinal; GLP, glucagon-like peptide.

\section{Competing interests}

JJM has received speaker and advisory board honoraria from Novo Nordisk, Ely Lilly, MSD, Novartis, Astra Zeneca, and Sanofi-Aventis.

\section{Published: 22 September 2010}

\section{References}

1. Deane A, Chapman MJ, Fraser RJL, Horowitz M: Bench-to-bedside review: The gut as an endocrine organ in the critically ill. Crit Care 2010, 14:228.

2. Opal SM, LaRosa SP: Year in review 2008: critical care - sepsis. Crit Care 2009, 13:224.

3. Kang W, Kudsk KA: Is there evidence that the gut contributes to mucosal immunity in humans? J Parenter Enteral Nutr 2007, 31:246-258.

4. Meier JJ, Nauck MA: Glucagon-like peptide 1(GLP-1) in biology and pathology. Diabetes Metab Res Rev 2005, 21:91-117.

5. Nauck MA, Heimesaat MM, Ørskov C, Holst JJ, Ebert R, Creutzfeldt W Preserved incretin activity of glucagon-like peptide 1 [7-36 amide] but not of synthetic human gastric inhibitory polypeptide in patients with type-2 diabetes mellitus. J Clin Invest 1993, 91:301-307.

6. Nauck MA: Is glucagon-like peptide 1 an incretin hormone? Diabetologia 1999, 42:373-379.

7. Meier JJ, Gallwitz B, Schmidt WE, Nauck MA: Glucagon-like peptide 1 as a regulator of food intake and body weight: therapeutic perspectives. Eur J Pharmacol 2002, 440:269-279.

8. Nauck MA, Meier JJ: Glucagon-like peptide 1 (GLP-1) and its derivatives in the treatment of diabetes. Regul Pept 2005, 124(Suppl):135-148.

9. Chaikomin R, Doran S, Jones KL, Feinle-Bisset C, O'Donovan D, Rayner CK, Horowitz M: Initially more rapid small intestinal glucose delivery increases plasma insulin, GIP, and GLP-1 but does not improve overall glycemia in healthy subjects. Am J Physiol Endocrinol Metab 2005, 289:E504-E507.

10. Nauck MA, Walberg J, Vethacke A, El-Ouaghlidi A, Senkal M, Holst JJ, Gallwitz B, Schmidt WE, Schmiegel W: Blood glucose control in healthy subject and patients receiving intravenous glucose infusion or total parenteral nutrition using glucagon-like peptide 1. Regul Pept 2004, 118:89-97.

11. Nikolaidis LA, Mankad S, Sokos GG, Miske G, Shah A, Elahi D, Shannon RP: Effects of glucagon-like peptide- 1 in patients with acute myocardial infarction and left ventricular dysfunction after successful reperfusion. Circulation 2004, 109:962-965.

12. Nauck MA, Kleine N, Ørskov C, Holst JJ, Willms B, Creutzfeldt W: Normalization of fasting hyperglycaemia by exogenous glucagon-like peptide 1 (7-36 amide) in type 2 (non-insulin-dependent) diabetic patients. Diabetologia 1993, 36:741-744.

13. Meier JJ, Weyhe D, Michaely M, Senkal M, Zumtobel V, Nauck MA, Holst JJ, Schmidt WE, Gallwitz B: Intravenous glucagon-like peptide 1 normalizes blood glucose after major surgery in patients with type 2 diabetes. Crit Care Med 2004, 32:848-851.

14. Mussig K, Oncu A, Lindauer P, Heininger A, Aebert H, Unertl K, Ziemer G, Haring HU, Holst JJ, Gallwitz B: Effects of intravenous glucagon-like peptide- 1 on glucose control and hemodynamics after coronary artery bypass surgery in patients with type 2 diabetes. Am J Cardiol 2008, 102:646-647.

15. Deane AM, Chapman MJ, Fraser RJ, Burgstad CM, Besanko LK, Horowitz M: The effect of exogenous glucagon-like peptide-1 on the glycaemic response to small intestinal nutrient in the critically ill: a randomised double-blind placebo-controlled cross over study. Crit Care 2009, 13:R67.

16. Schmidt WE: The intestine, an endocrine organ. Digestion 1997, 58(Suppl 1):56-58.

17. Mesotten D, Vanhorebeek I, Van den Berghe G: The altered adrenal axis and treatment with glucocorticoids during critical illness. Nat Clin Pract Endocrinol Metab 2008, 4:496-505.

doi:10.1186/cc9079

Cite this article as: Meier JJ: Waking up the gut in critically ill patients.

Critical Care 2010, 14:183 